\title{
OS INCENTIVOS FISCAIS NO CONTEXTO DO CONSTITUCIONALISMO DEMOCRÁTICO CONTEMPORÂNEO ${ }^{1}$
}

\author{
Leonardo Buissa Freitas* \\ Mateus Rocha de Lisbôa**
}

\begin{abstract}
RESUMO
O presente estudo abordará a questão da efetividade de programas de incentivo fiscal, a partir da análise da dialética da complementariedade, fundada na compreensão da teoria tridimensional do direito. Posto isso, adentra-se na análise do Constitucionalismo Contemporâneo, de caráter democrático, centrado na ideia elementar de direitos fundamentais, com destaque para a questão de sua efetividade e a intrínseca relação com as políticas públicas. Assim, os incentivos fiscais, instrumento dessas políticas cada vez mais em voga, devem enfrentar criteriosa análise, tendo por base a concretização dos direitos fundamentais.
\end{abstract}

PALAVRAS-CHAVES: Constitucionalismo Contemporâneo; incentivos fiscais; direitos fundamentais; efetividade.

\section{FISCAL INCENTIVES IN THE CONTEXT OF CONTEMPORARY DEMOCRATIC CONSTITUTIONALISM}

\begin{abstract}
This study will address the question of the effectiveness of tax incentive programs, based on the analysis of the dialectic of complementarity, based on the understanding of the threedimensional theory of law. That said it goes into the analysis of Contemporary Constitutionalism, of a democratic character, centered on the elementary idea of fundamental rights, with emphasis on the question of its effectiveness and the intrinsic relationship with public policies. Thus, tax incentives, an instrument of these policies that are increasingly in vogue, must face a careful analysis, based on the realization of fundamental rights.
\end{abstract}

KEY WORDS: Contemporary Constitutionalism; tax breaks; fundamental rights; effectiveness.

\section{INTRODUÇÃO}

\footnotetext{
${ }^{1}$ Este artigo faz parte de pesquisa científica desenvolvida junto ao programa de pós-graduação de Direito e Políticas Públicas da Universidade Federal de Goiás, com apoio institucional do PPGDP/UFG e seus financiadores.

* Doutor em Direito Econômico, Financeiro e Tributário/USP. Professor do PPGDP/UFG. Pesquisador no Projeto Finanças e Políticas Públicas: análises, planejamento e controle no contexto do Federalismo Fiscal cooperativo. Juiz Federal. Endereço postal: Alameda dos Jatobás, quadra 20, lote 06, Jardins Florença, Goiânia. CEP: 74351-018. Endereço eletrônico: leonardobuissa@gmail.com

** Mestrando em Direito e Políticas Públicas pela Universidade Federal de Goiás. Pós-graduando em Direito Tributário pela Universidade de São Paulo. Advogado. Endereço postal: Av. C-182, 370, apto 201, CEP 74.275020, Jardim América, Goiânia/GO. Endereço eletrônico: mateusrochalisboa95@ gmail.com
} 
A relação entre tributação e efetivação de direitos vem se construindo com elevado grau de intensidade nos últimos séculos, em especial a partir do momento em que emerge a ideia de Estado Fiscal, em um contexto em que a prestação de serviços públicos passa a ser cada vez função assumida pelo ente estatal.

Nesse cenário, o surgimento do Estado Social de Direito, caracterizada pela atuação ativa do ente público na efetivação de direitos, em contraposição à postura absenteísta que marcou o Estado Liberal, corroborou para a construção de um aparato estatal que assume progressivamente mais serviços públicos visando à efetividade dos direitos constitucionalmente previstos e assegurados aos cidadãos.

Dessa maneira, o Estado Fiscal se torna o mecanismo necessário para o sustento desse cenário sinteticamente acima exposto. Por meio da tributação o ente público logra recursos que serão destinados aos mais diversos serviços públicos, em sentido amplo, por ele assumidos, tais como educação, saúde, saneamento básico e transporte público.

Ocorre que o aumento da complexidade estatal, manifestada pelo crescente incremento de posturas e atividades assumidas por essa entidade, demanda uma atuação casuística e centrada nas especificidades de cada setor abrangido por suas fronteiras, sob pena de assunção de modelos incompatíveis com certas realidades em específico.

Justamente em razão de fatores casuísticos inerentes às desigualdades socioeconômicas vivenciadas entre os Estados brasileiros tem-se vivenciado uma nova cenário para a tributação: no lugar do aumento da carga tributária para o financiamento de políticas públicas sociais constata-se a utilização do tributo como instrumento indutor voltado para a efetividade e concretização de valores constitucionais.

Assim, ao longo do século XX, em especial no período posterior à Constituição de 1988, com a maior descentralização política e o aumento da autonomia dos entes federados, observa-se no Brasil o fenômeno intitulado de incentivo fiscal, instrumento assumido pelos Estados membros para a atração de maiores investimentos em seus territórios, diante de notórias desigualdades regionais que marcam o Estado brasileiro.

Nessa perspectiva, o presente estudo apresenta como objetivo prioritário a compreensão do fenômeno jurídico dos incentivos fiscais no contexto do Constitucionalismo Contemporâneo. Ademais, como objetivos específicos, apresenta a análise do fenômeno jurídico a partir da dialética da complementariedade, o estudo dos direitos fundamentais 
enquanto categoria inserida no Constitucionalismo Democrático, bem como o exame das políticas públicas e a crítica feita com base na ideia da efetividade.

Para tanto, este estudo recorrer-se-á à revisão da literatura, de modo a tornar compreendidos os conceitos centrais da pesquisa, utilizando método dedutivo, partindo-se da análise conceitual geral a aferição particular e casuística dos incentivos fiscais no contexto do Constitucionalismo Contemporâneo.

Observa-se a crescente relevância do problema acima exposto, tendo em vista o conflito que surge entre os dois polos gerados pelos incentivos fiscais: de um lado, renúncia de receita em um Estado com consideráveis responsabilidades sociais; de outro, o incremento na economia que tais incentivos podem trazer. Assim, constata-se a relevância desta pesquisa, diante da necessidade de se lograr cada vez mais eficiência com os gastos públicos e efetividade na concretização de direitos fundamentais.

\section{A DIALÉtiCA DA COMPLEMENTARIEDADE E A ANÁliSE DOS PROGRAMAS DE INCENTIVO FISCAL}

A devida compreensão de determinado problema jurídico, em especial quando se trata de analisar efeitos que se inserem na esfera fática dos acontecimentos humanos, exige arcabouço teórico que possibilite o estudo de maneira ampla e completa, não consistindo em acepções unidirecionais da problemática que, por si só, manifesta-se de maneira complexa.

Nesse aspecto, a teoria tridimensional do Direito desenvolvida por Miguel Reale em sua dialética da complementariedade possibilita a compreensão do fenômeno jurídico em apreço em toda sua complexidade, desde os aspectos fáticos e axiológicos até as questões normativas propriamente ditas.

Tal perspectiva remonta ao culturalismo realista adotado e definido pelo referido jurista (REALE, 2000, p. 3), como uma compreensão do Estado e do Direito integrada ao historicismo contemporâneo, aplicando ao estudo dessas duas experiências culturais princípios da Axiologia enquanto teoria dos valores em função dos graus de evolução social.

A acepção do jurídico enquanto realidade fática sobre a qual incide aspectos axiológicos assumida destaca a superação das dicotomias existentes na teoria do Direito (REALE, 1992, p. 107-108): de um lado, análises de cunho mais sociológico, focadas na compreensão exclusiva do fenômeno social envolto à questão, e, de outro, estudos de natureza 
eminentemente normativa, centrados prioritariamente em aspectos lógicos e formais do Direito.

Definitivamente, a experiência jurídica não se enquadra em nenhuma dessas perspectivas de maneira exclusiva. Assim sendo, qualquer pesquisa na área do Direito, independentemente do enfoque por ela conferido, deve ser (REALE, 2010, p. 48), necessária e essencialmente, tridimensional, implicando na impossibilidade de se conceber a apreciação de fato, valor e norma como elementos inseparáveis da experiência jurídica.

O fato de o Direito ser constituído por esses três elementos, não implica necessariamente na existência de uma única Ciência jurídica. Ao contrário, sua unidade advém de uma unidade de processus (REALE, 2010, p. 56), por natureza dialética e histórica. Dessa forma, a conduta jurídica não é constituída por três elementos abstratos e independentes, mas sim de três fatores que se relacionam dialeticamente, em determinado momento histórico, corroborando, assim, para o surgimento do Direito enquanto experiência humana e social.

A devida compreensão jurídica exige, portanto, necessariamente a constatação dos três fatores em conjunto, podendo-se sintetizar, nos dizeres de Miguel Reale, a experiência jurídica como a correlação de natureza funcional e dialética, "dada a 'implicação-polaridade' existente entre fato e valor, de cuja tensão resulta o momento normativo, como solução superadora e integrante nos limites circunstanciais de lugar e de tempo (concreção histórico do processo jurídico, numa dialética de complementariedade)."

No presente estudo, torna-se imperiosa a abordagem naturalmente complexa que se propõe fazer com fundamento na teoria realeana. Diante do problema levantado, qual seja, a eficiência dos programas de incentivo fiscal no Brasil, a pesquisa a ser empreendida necessariamente deverá englobar compreensões de ordem fática e axiológica, não se limitando aos contornos exclusivamente normativos dos referidos programas.

Assim sendo, delimita-se, inicialmente, sob tais aspectos, os momentos atinentes aos fatos, aos valores e às normas componentes do fenômeno jurídico em estudo.

\subsection{O momento fático da República Federativa do Brasil}

Conforme exposto alhures, a experiência jurídica pressupõe dada realidade fática, sobre a qual incidirão aspectos axiológicos, fazendo emergir, assim, o momento normativo. 
Nessa seara, prioritário se torna o estudo do momento fático relativo ao problema proposto, delimitando as questões essenciais que marcam os programas de incentivo fiscal.

Dessa maneira, a compreensão histórica da formação socioeconômica do Brasil se torna fundamental. Impossível empreender qualquer estudo de incentivos fiscais sem, ao menos, se ter em mente a origem da problemática que levou o constituinte de 1988 a positivar na Carta Magna (artigo 155, $\S 2^{\circ}, \mathrm{XII}, g, \mathrm{CF} / 88$ ) a possibilidade de os entes federados instituírem incentivos fiscais para o combate à desigualdade regional do país (artigo $3^{\circ}$, III, $\mathrm{CF} / 88)$.

Remonta-se, assim, à análise empreendida por Celso Furtado, diante da qual se constata, empiricamente, o processo de concentração de renda e riqueza experimentada pelo Estado brasileiro ao longo do século XX. Tal processo restou marcado sobretudo pelo acentuado desenvolvimento do setor industrial na região Sudeste, em virtude, especialmente, da prosperidade da economia cafeeira.

Assim, conforme dados ${ }^{2}$ relativos ao índice de industrialização, renda per capita e porcentagem de operários industriais apresentados pelo mencionado autor, contata-se a elevada concentração de renda que passou a existir no Brasil a partir do século XX: "Se, pela metade do século, a economia brasileira havia alcançado um certo grau de articulação entre as distintas regiões, por outro a disparidade de níveis regionais de renda havia aumentado notoriamente" (FURTADO, 2007).

Dessa maneira, o cenário socioeconômico dos Estados brasileiros ao longo do século XX caracteriza-se, dentre outros fatores, pela elevada concentração de riqueza na região Sudeste, bem como pela notória desigualdade regional que foi sendo construída.

Tal fator possui implicações relevantes para a construção social experimentada pelo Estado brasileiro. Nesse sentido, na realização de estudo da desigualdade no mundo, Thomas Piketty aponta que a história da desigualdade remonta aos atores políticos, sociais e econômicos e sobre o que tais atores compreendem ou não como justo, influenciando diretamente nas escolhas coletivas realizadas. Em suma, a desigualdade "é fruto da combinação, do jogo de forças, de todos os atores envolvidos" (PIKETTY, 2014). Tal tese, de fato, é comprovada pela experiência histórica brasileira, tendo em vista os constantes aportes

\footnotetext{
${ }^{2}$ Destaca-se que o índice de operários industriais no Estado de São Paulo saltou de 29,1\% (1920) para 34,9\% (1940) e 38,6\% (1950). A respeito da participação do Estado paulista na indústria nacional passou de 39,6\% para 45,3\% entre 1948 e 1955. E com relação à renda per capita, em 1955, o Estado de São Paulo desfrutava de índice 4,7 vezes maior que da região nordestina (FURTADO, 2007, p. 329).
} 
financeiros realizados pelo Estado ao longo da República Velha no sentido de salvar a cultura cafeeira.

A questão da desigualdade é prioritária nos debates socioeconômicos atuais, tendo em vista a intrínseca relação existente entre o real desenvolvimento e a liberdade (SEN, 2010). Nesse sentido, conforme estudo de Amartya Sen, a liberdade, composta por cinco perspectivas distintas, quais sejam, a política, a de facilidade econômica, a social, a garantia de transparência e a segurança protetora (SEN, 2010), as quais se relacionam diretamente contribuindo para o real desenvolvimento humano, calcado na liberdade humana em geral.

Ademais, realizando análise mais concreta da questão, pode-se apontar que o desenvolvimento econômico se torna fundamental para a questão da liberdade, ainda que não seja fator exclusivo. Isso porque a insegurança econômica pode relacionar-se com a ausência de direitos e de liberdade democrática (SEN, 2010).

Portanto, a questão da desigualdade regional brasileira não consiste em mero debate abstrato de índices socioeconômicos. Ao contrário, se torna prioritário para a devida efetividade que se visa conferir a direitos fundamentais constitucionalmente assegurados, conforme restará melhor desenvolvido a seguir.

\subsection{O momento axiológico e a questão do valor em Miguel Reale}

A compreensão do aspecto axiológico na teoria tridimensional do Direito requer novo substrato teórico e específico com relação a este ponto para a devida compreensão da matéria. Nesse aspecto aponta-se a teoria dos valores de Miguel Reale, abordando aspectos do historicismo axiológico construído pelo referido autor.

A partir de tal perspectiva possibilita-se a constatação do valor enquanto realidade autônoma na teoria dos objetos, tendo em vista sua peculiaridade frente aos objetos naturais (físicos e psíquicos) e ideais (MARTINS, 2008). Tais peculiaridades remontam ao fato de os valores serem desprovidos de espacialidade e temporalidade, assim como os objetos ideais, mas destes diferindo em razão de necessitar de algo existindo anteriormente, tido pelo autor como as coisas valiosas, de não ser passível de quantificação e de ser insuscetível de definição. De todo modo, os valores situam-se na teoria dos objetos, sendo possível desenvolver-se estudo a seu respeito.

Ainda a respeito dos aspectos teóricos da categoria valor, devem ser pontuadas duas de suas características: em primeiro lugar a sua bipolaridade, de modo que todo valor possui 
um desvalor que lhe contrapõe; em segundo lugar, com base no personalismo axiológico, compreende-se que os valores, na sua gênese, possuem como fundamento a pessoa humana (MARTINS, 2008).

Diante desse cenário teórico dos valores, se torna possível a compreensão dos aspectos axiológicos atinentes aos programas de incentivo fiscal. Assim, o momento axiológico do cenário fático acima exposto remonta à percepção da latente desigualdade que foi sendo intensificada no Estado brasileiro ao longo do século XX. Diante disso realçam-se valores relativos à construção de uma sociedade livre, justa e solidária (artigo $3^{\circ}, \mathrm{I}, \mathrm{CF} / 88$ ), à garantia do desenvolvimento nacional (artigo $3^{\circ}, \mathrm{II}, \mathrm{CF} / 88$ ) e à erradicação da pobreza e da marginalização, bem como, sobretudo, à redução das desigualdades sociais e regionais (artigo $3^{\circ}$, III, CF/88), todos esses alçados como objetivos fundamentais da República Federativa do Brasil pela Constituição Federal de 1988.

Tais valores, na perspectiva da desigualdade regional brasileira, implicam na construção normativa de mecanismos que possibilitem o pleno e integral desenvolvimento do território nacional, de modo que as regiões historicamente marginalizadas do eixo central de desenvolvimento pátrio possam lograr o devido crescimento socioeconômico almejado.

Essa perspectiva remonta, consequentemente, à questão da efetividade e legitimidade normativa, em especial quando se trata de políticas públicas construídas para determinado fim, conforme restará aprofundado abaixo.

Nesse sentido, a respeito da validade do Direito (REALE, 2010), Miguel Reale destaca os três fios que o compõe: a vigência, relacionado à obrigatoriedade formal dos preceitos jurídicos (aspecto normativo da teoria tridimensional), a eficácia, referente à correspondência social ao conteúdo da norma (aspecto fático) e o fundamento, remontando aos valores capazes de legitimá-los numa sociedade de homens livres (aspecto axiológico).

Assim sendo, com relação ao fundamento ou à legitimidade componente da validade do Direito, constata-se que os programas de incentivo fiscal instituídos pelos Estados membros da Federação brasileira manifestam-se como legítimos e fundados sob o aspecto axiológico, tendo em vista que o pleno desenvolvimento nacional e a redução da desigualdade regional são valores caros à realidade brasileira contemporânea.

No entanto, outros valores incidem sobre o momento fático acima discorrido. Assim, questões relativas ao federalismo cooperativo brasileiro, à responsividade fiscal e à necessidade de arrecadação tributária para a implementação de outras políticas públicas 
também são aspectos que devem ser considerados e sopesados nessa discussão, enriquecendo o debate acerca da legitimidade dos incentivos fiscais.

Entretanto, tendo em vista o personalismo axiológico supramencionado, percebe-se que o combate à desigualdade regional brasileira, que remonta diretamente às condições dignas de vida de todos os seus cidadãos, relacionando-se de maneira prioritária com a pessoa humana enquanto fundamento de toda ordem valorativa, acaba por se sobrepor às questões de estrutura de Estado, as quais se relacionam com a pessoa humana com menor grau de intensidade ou de maneira mais indireta, devendo-se regredir a outras valores anteriormente para que se alcance a pessoa humana como centro e ponto de partida valorativo.

\subsection{O momento normativo e os programas de incentivo fiscal}

Por fim, quanto ao momento normativo oriundo da incidência de valores relativos à redução da desigualdade regional e ao desenvolvimento nacional sobre a realidade historicamente desigual do Estado brasileiro emergem programas de incentivo fiscal por diversos Estados membros, visando ao incremento socioeconômico destes estes da Federação.

Para compreensão desses incentivos, o momento normativo necessita de ponderações a respeito da experiência da linguagem, tendo em vista sua natureza eminentemente descritiva, atrelada à capacidade comunicativa e retórica do ser humano.

Diante da perspectiva dialética e histórico-cultural da linguagem, constata-se a precípua ligação entre "língua" e "fala", remontando à questão da análise fenomenológica da consciência enquanto manifestação da intencionalidade (REALE, 2000). Assim, a linguagem, enquanto faculdade de simbolizar a intencionalidade humana, consiste na raiz de todo o processo cultural.

Dessa perspectiva pode-se construir a compreensão retórica da filosofia jurídica, tendo como pressuposto básico a questão da linguagem. Explica-se. Para a filosofia retórica, a linguagem não consiste em um meio para o mundo real, sendo, ao contrário, o único meio perceptível (ADEOTADO, 2011), de modo que todo conhecimento é formado por acordos linguísticos intersubjetivos, essencialmente circunstanciais, temporários, autorreferentes e passíveis de constantes rompimentos.

A consequência disso, na acepção jurídica, remonta à perquirição dos sentidos existentes nas normas jurídicas, o contexto em que surgiram (complexo axiológico incidente 
sobre o momento fático, na perspectiva realeana) e a maneira como foi construído determinado sentido (ADEOTADO, 2011).

Essa visão crítica da norma jurídica enquanto tal se torna fundamental na medida em que se constrói uma visão retórica do Direito pautada em uma tripla acepção da norma: esta analisada enquanto expressão simbólica dotada de validade (significante), enquanto ideia (significado) e, enfim, enquanto decisão dotada de efetividade.

\section{O CONSTITUCIONALISMO DEMOCRÁTICO CONTEMPORÂNEO}

Conforme exposto acima, segundo entendimento advindo da teoria tridimensional do Direito de Miguel Reale, a experiência jurídica deve ser compreendida como fruto da relação dialética entre fato e valor, emergindo, dessa polaridade, o momento normativo, concretizando, assim, o fenômeno jurídico em sua completude.

Dessa forma, cabe realizar análise do atual estágio da experiência jurídica contemporânea, compreendida como Constitucionalismo Democrático, destacando-se suas principais características, em especial o maior relevo atribuído aos direitos fundamentais, para, em conseguinte, operar-se estudo de sua relação com a instituição de programas de incentivos fiscais pelos Estados membros brasileiros.

Assim sendo, para a devida compreensão da experiência jurídica atual se torna necessária a análise do Estado Contemporâneo. Este resta caracterizado, prioritariamente, pela complexa coexistência entre Estado de direito, de origem burguesa, e Estado social, advindo das demandas populares no período pós Revoluções Industriais (GOZZI, 2007). Tal complexidade resulta da distinção entre direitos fundamentais em sua concepção tradicional, enquanto tutela das liberdades burguesas, as quais exigem prestação absenteísta do Estado, e direitos sociais, representando direitos que exigem prestações positivas do Estado, bem como demandam maior participação no poder político. Em suma, o Estado Contemporâneo resulta da oscilação entre a liberdade e a participação.

Esse cenário se densifica em complexidade a partir das transformações advindas das revoluções burguesas. Isso porque o Estado Absoluto deixa de ser o proprietário de, os quais passam para as mãos dos particulares. Assim, para o custeio da máquina púbica e, a partir dos séculos XIX e, em especial, XX, para a prestação dos serviços públicos necessários à efetividade dos direitos sociais, emerge a necessidade de instituição do Estado Fiscal, o qual se torna elemento central na análise do Estado Contemporâneo (GOZZI, 2007). 
Nesse sentido, a questão dos direitos fundamentais surgem no contexto do Estado Contemporâneo como aspecto central, manifestando-se como fruto de duas fontes filosóficas de valores: a da liberdade, relativas às garantias burguesas de primeira geração, e a da igualdade, oriundas das prestações estatais consolidadas no século XX (MOREIRA NETO, 2006).

O Constitucionalismo Contemporâneo, portanto, pode ser construído, em suma, sobre quatro pilares básicos (MOREIRA NETO, 2006), quais sejam, o dos direitos fundamentais, enquanto fator determinante para o reequilíbrio das relações entre sociedade e Estado no pós guerra; a subsidiariedade, como fator de reorganização entre Estado e sociedade; a legitimidade, elemento essencial para a efetividade dos direitos fundamentais; e o conceito de Constituição como ordem de valores.

Nessa seara, a relação entre Constitucionalismo Contemporâneo e democracia é umbilical, tendo em vista que aquele se manifesta a partir ampla gama de valores econômicos, sociais e culturais que passam a ser albergados nas Constituições, tornando a questão da legitimidade democrática elemento crucial no Estado Contemporâneo. Nesse aspecto, pode abstrair o Constitucionalismo democrático como uma "fórmula política baseada no respeito aos direitos fundamentais e no autogoverno popular", além de um "modo de organização social fundado na cooperação de pessoas livres e iguais” (BARROSO, 2019).

Feitas tais ponderações prioritárias a respeito do Constitucionalismo Contemporâneo, adentra-se agora no estudo de seu elemento de maior destaque, isto é, os direitos fundamentais e sua ínsita relação com a questão da efetividade. Para tanto, deve-se pontuar, primeiramente, a maneira como se processará a atuação do Estado nesse cenário.

\subsection{A norma jurídica e as normas de direitos fundamentais}

Antes de adentrar na questão da efetividade propriamente dita, deve-se ponderar a respeito da estrutura das normas jurídicas de maneira geral e das de direito fundamentais de maneira específica, ponto no qual será por ora realizado.

Conforme já abordado acima e retomado de maneira pormenorizada por agora, a teoria retórica da norma jurídica indica que esta pode ser compreendida sobre tripla acepção: um tipo de ideia significada, como fonte do direito significante e como decisão concreta. Isso implica na acepção de norma enquanto promessa jurídica, isto é, um para o futuro, no qual a sua “obrigatoriedade e adimplência dependerá das condições empíricas do futuro", de tal 
modo que o relevante nesse contexto será o "cumprimento da promessa realizada, através do controle da complexidade e da construção de uma cooperação atual” (ADEODATO, 2011).

Portanto, para tal teoria da norma jurídica, esta manifesta-se, primeiramente, enquanto significado, dotada de promessas dirigidas ao futuro, sendo carregada de elementos estruturais constantes (functor deôntico dever ser e a distinção entre licitude / ilicitude), bem como de um função, centrada na complexidade da conduta humana intersubjetiva, buscando limitá-la, controlando-se atividades futuras que ainda não existem (ADEODATO, 2011). Portanto, sob o aspecto da norma jurídica enquanto ideia (significado), ela se manifesta por meio de suas estruturas e de sua função, sempre voltada para o futuro.

Com relação à segunda acepção da norma jurídica, enquanto expressão simbólica dotada de validade (significante), concebe-se a norma jurídica a partir do ponto de vista da teoria da linguagem, sendo composta por elementos predicadores e indicadores, visando delimitar seu campo de incidência e compreensão (ADEODATO, 2011).

Por fim, com relação à compreensão da norma jurídica como decisão dotada de efetividade, destaca-se o momento em que a norma jurídica se concretiza, envolvendo posicionamento ético obrigatório e também uma técnica (ADEODATO, 2011). Após o exercício dessa capacidade decisória a norma jurídica influi novamente no mundo dos eventos, de onde retirou as condutas que elegeu por meio de seus significantes como relevantes para o mundo jurídico.

Portanto, sob tal perspectiva da teoria retórica da norma jurídica, constata-se que envolverá a escolha de condutas relevantes para o direito, por meio de uma estruturação ideal com que se reveste, voltada para a concretização futura de valores anteriormente estabelecidos. A questão dos direitos fundamentais, assim, emerge de modo destacado, diante da estruturação com que as normas de tais direitos se consolidam (significado), a partir do recurso linguístico escolhido em determinado contexto da sociedade humana (significante) e tendo em vista a constante busca de sua concretização através da acepção da norma jurídica enquanto decisão.

Nesse sentido, a respeito da questão da estrutura da norma jurídica de direito fundamental (norma enquanto significado), cabem determinadas ponderações. A primeira delas diz respeito a distinção entre regras e princípios, adotando-se a tese de que entre tais espécies normativas existem diferenças não apenas de graduação na generalidade, como também na qualidade (ALEXY, 1985). 
Dessa maneira, princípios são mandamentos de otimização, devendo ser realizados na maior medida do possível, tendo em vista as condições jurídicas e fáticas atinentes ao contexto em questão, podendo, por isso, ser satisfeitos em graus variados. Os limites para tanto serão os de ordem fática e jurídica, devendo estes ser delimitados pelos princípios e regras colidentes (ALEXY, 1985). Ao contrário, as regras consistem em determinações fáticas e jurídicas, sendo satisfeitas ou não, conforme sua validade (ALEXY, 1985).

Justamente nesse contexto em que se insere o objeto desta pesquisa, qual seja, a necessidade de se avaliar as políticas públicas de incentivos fiscais frente à concretização de direitos fundamentais.

\subsection{Os direitos fundamentais e sua efetividade}

Compreendida a estrutura dos direitos fundamentais enquanto normas jurídicas que assumem aspectos de princípio e de regra, incidindo sobre tais espécies distintos mecanismos para lidar com suas peculiaridades, visando sempre à máxima concretização dos direitos fundamentais assegurados, deve-se, enfim, compreender a questão central de toda a problemática, voltada para a efetividade de tais direitos.

A questão da efetividade dos direitos fundamentais manifesta-se como de prioritária relevância para o presente estudo tendo em vista que o substrato legitimador dos programas de incentivo fiscal consistem, justamente, na concretização de valores constitucionais elevados a nível fundamental. Nesse sentido, a escolha empreendida pelas políticas públicas se torna temática central no constitucionalismo contemporâneo, justamente em razão do grau de eficiência juridicamente estimável dessas políticas, assim como do seu grau de efetividade social (MOREIRA NETO, 2006).

A teoria dos direitos fundamentais aponta para a dignidade humana, postulado em que se assenta o direito constitucional contemporâneo (SARLET, 2006) e informador de toda a ordem jurídica (SARLET, 2006), seu substrato lógico e estrutural, de modo que a efetividade de direitos fundamentais consiste, em primeira e última análise, justamente na concretização do princípio da dignidade da pessoa humana.

Dessa forma, diante da concepção que estabelece como fundamento do ordenamento jurídico o conceito de dignidade da pessoa humana, constata-se que o mecanismo constitucional elaborado para a concretização de tal fundamento manifesta-se, sobretudo, por 
meio da efetividade de direitos fundamentais, tornando tal disciplina de considerável relevância no estudo do direito contemporâneo.

A questão da efetividade, assim, surge a partir da compreensão de determinados conceitos elementares no direito constitucional contemporâneo, quais sejam, o da existência, da vigência, da validade e da eficácia (SARLET, 2010) no contexto da aplicabilidade das normas jurídicas.

Nesse sentido, a ideia de existência refere-se à presença dos elementos constitutivos da norma (agente, forma e objeto), enquanto a vigência manifesta-se como qualidade da norma que existe, estando ligada a existência do ponto de vista jurídico. Por sua vez, a validade diz respeito ao atendimentos dos requisitos estabelecidos pelo ordenamento jurídico no momento de produção da norma.

A questão da efetividade surge, assim, no seio do quarto atributo da norma jurídica: o da eficácia. Dessa maneira, eficácia e vigência possuem correlação dialética de complementariedade, de modo que da eficácia extraem-se duas percepções distintas - a jurídica, relacionando-se com a produção de efeitos jurídicos, e a social, esta sendo compreendida como a efetividade propriamente dita (SARLET, 2010).

Portanto, a efetividade da norma jurídica pode ser conceituada (SARLET, 2010) como "a realização do Direito, o desempenho concreto de sua função social", representando "a materialização, no mundo dos fatos, dos preceitos legais e simboliza a aproximação tão íntima quanto possível, entre o dever ser normativo e o ser da realidade social”.

\section{O ESTUDO DAS POLÍTICAS PÚBLICAS}

No atual contexto do constitucionalismo democrático, emergem as políticas públicas, enquanto instrumento para efetividade de direitos fundamentais, a um papel central e de protagonismo, tornando-se cada vez maior a literatura e os estudos a respeito dessa temática, eminentemente complexa e interdisciplinar.

As políticas públicas, de origens que remontam às Ciências Sociais e à Ciência da Administração Pública (BUCCI, 2006), tornaram-se objeto de estudo da ciência jurídica a partir do surgimento de direitos sociais, ganhando maior força e destaque com a constitucionalização de tais direitos, em especial a partir da Constituição Federal de 1988 (BUCCI, 2006). Nesse cenário, diante da baixa efetividade desses direitos, a categoria 
"políticas públicas" se torna, também, objeto de estudo do Direito, sob pena de se ferir, diretamente, a própria densidade normativa das normas jurídicas.

Dessa forma, as políticas públicas assumem diversas formas do ponto de vista normativo, podendo estar estruturadas por meio de disposições constitucionais, legais, infralegais ou, até mesmo, por meio de atos normativos de natureza diversa, como contratos de concessão de serviço público (BUCCI, 2006). Em suma, o que define a natureza da política pública não é o ato normativo que a insere no ordenamento jurídico, mas sim o fato de consistir em um "programa ou quadro de ação governamental", sendo materializada através de um conjunto de "medidas articuladas e coordenadas, cujo escopo é dar um impulso, isto é, movimentar a máquina do governo, no sentido de realizar algum objetivo de ordem pública ou, na ótica dos juristas, concretizar um direito" (BUCCI, 2006).

Assim sendo, as políticas públicas podem ser compreendidas como programas de ação destinadas a realização de direitos, não sendo uma categoria exclusivamente jurídica, mas caracterizada também por seus traços de atividade político-administrativa, de modo que se torna possível sua compreensão como arranjos complexos.

Nesse contexto, pode-se conceber as políticas públicas enquanto arranjos jurídicosinstitucionais, dotadas de significado funcional, integrando um conjunto complexo de normas, atores, processos e instituições jurídicas. Essa perspectiva das políticas públicas a partir da lente do Direito possibilita compreendê-las como arranjos institucionais, expressões particulares de organização da ação governamental em função de objetivos determinados, sendo que as engrenagens hábeis a colocar em funcionamento tais ações de governo possuem natureza jurídica (BUCCI e COUTINHO, 2017).

Essa perspectiva possibilita o exercício da análise funcional das políticas públicas, voltando-se para a compreensão das normas infralegais, tendo em vista seu relevante papel na definição do procedimento e na concretização dos comandos mais abstratos dos programas instituidores das políticas públicas. Em suma, a análise sob a concepção de arranjos jurídicoinstitucionais se torna, no contexto brasileiro de fundamental importância, pois é justamente por meio desse ângulo que poderá se analisar e criticar a aplicação satisfatória da base normativa das políticas públicas, bem como sua implementação.

\subsection{Incentivos fiscais: políticas públicas para o combate à desigualdade regional brasileira}


Para compreender os incentivos fiscais enquanto mecanismo para combate à desigualdade regional brasileira, deve-se, anteriormente, conceber a intrínseca relação que se forma entre Direito Financeiro, Estado e direitos fundamentais.

O exercício da atividade financeira por parte do Estado remonta desde os mais remotos tempos, não emergindo apenas com o surgimento do Estado Moderno. Ao contrário, desde Aristóteles constata-se referências à regulação das finanças públicas (SCAFF, 2018), no sentido de administrar e executar os recursos obtidos pelo ente público. Cabe mencionar que desde tal período histórico encontram-se menções a instrumentos de transparência fiscal, assim como preocupações com os gastos advindos das guerras.

A relação entre esses três elementos só se manifesta de maneira completa no século $\mathrm{XX}$, momento histórico no qual o Estado, por meio de seu aparato jurídico-financeiro, assume a implementação de políticas públicas sociais, voltadas, justamente, para a efetividade de direitos fundamentais (SCAFF, 2018).

No contexto de construção desse Estado notoriamente fiscal, o qual necessita da arrecadação tributária para poder efetivar os direitos positivados em seu ordenamento, a atividade arrecadatória estatal assume cada vez mais lugar de destaque. Em um primeiro momento, tal exercício se dá por meio elaboração de mecanismos diversos, voltados sempre para a construção de um sistema tributário mais eficiente e com maior volume de arrecadação.

No entanto, o poder de tributar, aos poucos, passou a ser compreendido também como mecanismo a ser utilizado de maneira a fomentar determinados valores elencados como relevantes para os objetivos estatais. Assim, o poder de tributar, enriquecendo em complexidade, passa a não mais se resumir a um instrumento de provimento de recursos financeiros, como também se torna possiblidade de fomento e desenvolvimento de determinadas atividades a serem construídas em colaboração com o particular.

Essa nova perspectiva do poder de tributar ganha destaque no contexto de desigualdades regionais. Diante desses problemas de ordem política e social, o Estado, buscando soluções para levar desenvolvimento a todo o conjunto da economia nacional, passa a utilizar a tributação para o atingimento de finalidade atípica: fomentar e incentivar o agente privado a investir em determinadas zonas de seu território, notoriamente aquelas nas quais em que a desigualdade regional se manifesta de maneira mais intensa.

Nesse sentido, diante do processo de formação econômica brasileira, marcada pela criação de regiões destacadamente desenvolvidas, em detrimento de outras em estagnação 
econômica (BERCOVICI, 2001), o campo dos incentivos fiscais, enquanto utilização fomentadora do tributo, ganhou grande destaque na conjuntura nacional ao longo do século XX, em especial a partir da Constituição Federal de 1988, por motivos a seguir expostos a respeito do federalismo fiscal brasileiro.

Em suma, o aspecto prioritário de tais incentivos consiste na sua feição de fomento, o que permite concebê-lo, em uma perspectiva normativa, como "norma jurídica indutora que opera como fator de alavancagem ao agente econômico, implicando um incentivo na adoção de determinada postura negocial" (BEVILACQUA, 2013).

\subsubsection{O federalismo fiscal brasileiro}

Os incentivos fiscais tornaram-se instrumentos reiteradamente utilizados pelos Estados-membros a partir da segunda metade do século XX, em especial após a Constituição Cidadã, por dois motivos prioritários, um de ordem histórica e outro de caráter políticojurídico.

Primeiramente, a questão da desigualdade regional brasileira nunca foi tratada de maneira satisfatória, sempre sendo relegada para um plano secundário, complementar e compensatório (BERCOVICI, 2001). A centralidade política na esfera federal, a histórica concentração de riqueza em determinados polos regionais civilizatórios e o tratamento conferido às regiões de fronteira, com menor desenvolvimento socioeconômico, tornaram-se o gargalo que vêm impedindo, ao longo dos séculos, um integral desenvolvimento nacional.

Evidentemente, o problema que envolve a questão não é a ausência de políticas para a correção desse obstáculo. Ao contrário, desde o período imperial, ações governamentais nesse sentido não faltaram. O cerne do debate encontra-se, justamente, na maneira com que se realizou tais ações, focadas, sobretudo, na centralização política e em práticas exclusivamente de atração de indústrias, sem se preocupar com a concretização das ideias de desenvolvimento com liberdade, de Amartya Sen.

Já o aspecto político-jurídico remonta ao federalismo brasileiro, que desde a proclamação da República sempre se assentou na centralidade dos poderes da União, em detrimento da maior repartição de competências. Dessa forma, com o advento da Constituição de 1988 e a consolidação do federalismo cooperativo, os Estados passaram a assumir maior protagonismo, podendo elaborar suas próprias políticas públicas desenvolvimentistas. 
Nesse contexto, o federalismo cooperativo brasileiro ganha notoriedade, podendo, primeiramente, compreendê-lo como a "atribuição (de funções) a todas as ordens jurídicas de competência para tratamento da mesma matéria (competência comum ou concorrente), gerando uma necessária intervenção e cooperação entre os entes da federação, inclusive com a repartição vertical das receitas tributárias” (MOREIRA, 2016).

O federalismo fiscal brasileiro é conceituado como cooperativo justamente em razão da necessidade de repartição do produto da arrecadação e do sistema de transferências intergovernamentais (CONTI, 2010), diante da incapacidade de as atribuições de competência tributária servir, isoladamente, para o sustento de todos os entes federados. Dessa forma, percebe-se que o valor que serve de substrato ao federalismo cooperativo é justamente o princípio da solidariedade e na garantia do bem-estar (TORRES, 2014), valores centrais do Estado Social de Direito.

Compreendidos os traços prioritários do federalismo fiscal, constata-se que os incentivos fiscais de ICMS por parte dos Estados com menor índice de desenvolvimento socioeconômico tornaram-se instrumentos de maior incidência nas últimas décadas, em virtude, sobretudo, da ausência de ações concretas por parte do ente federal e das maiores competências tributárias conferidas aos Estados membros.

\subsection{Direitos fundamentais e tributação}

Por fim, compreendida a natureza dos incentivos fiscais e do federalismo cooperativo brasileiro, deve-se pontuar a respeito da relação desse instrumento normativo indutor com a desigualdade regional, direitos fundamentais, políticas públicas e tributação.

A relação entre direitos fundamentais e tributação é umbilical, tendo em vista a necessidade de o ente público angariar recursos para o sustento das políticas públicas voltadas para a concretização de tais direitos, diante da concepção de custos dos direitos acima exposta.

Assim, parte-se o presente estudo da atual compreensão do poder de tributar, como sendo um sistema de direitos e deveres fundamentais, fundado na ética material (CALIENDO, 2017). Segundo essa perspectiva, o poder de tributar apresenta dupla faceta: de um lado, dever fundamental do indivíduo, enquanto integrante do todo social, correspondendo, assim, à acepção prestacional da cidadania; de outro, direito fundamental, consubstanciado, em suma, 
por meio das normas constitucionais de limites ao poder de tributar previstas na Constituição Federal, impondo balizas normativas à atuação arrecadatória do Estado.

Os direitos fundamentais manifestam-se diretamente também com a desigualdade regional. Os índices sociais que os Estados das regiões Centro-Oeste, Norte e Nordeste apresentam diferem-se, sobremaneira, daqueles ostentados pelas regiões Sul e Sudeste. A concretização de direitos fundamentais básicos, tais como educação, saúde e moradia, necessitam de combate à concentração de riquezas no Estado federal brasileiro, por meio, obviamente, da ascensão dos Estados "periféricos”.

O combate a essa latente desigualdade regional brasileira não se restringe, naturalmente, a concessão desenfreada de incentivos fiscais de ICMS. Ao contrário, o intuito da presente pesquisa é justamente estabelecer controle e análise crítica sobre tal modalidade de intervenção estatal na economia.

A correção desse vício histórico brasileiro só poderá ser possível através da implantação de políticas públicas eficientes. A utilização de incentivos físcais para tanto não pode assumir um valor em si mesmo, devendo ser apenas um mecanismo pertencente a um programa maior, amplo e concreto, que vise levar definitivamente a prosperidade a todos os rincões brasileiros.

\section{CONCLUSÃO}

Por meio da dialética da complementariedade, no contexto da teoria tridimensional do direito, concebe-se a compreensão ampla e integral da experiência jurídica, a qual não pode ser limitada a seus aspectos fáticos / sociológicos, axiológicos ou normativos. Ao contrário, a experiência jurídica engloba, dialeticamente, a relação que essas três categorias desenvolvem entre si, de maneira naturalmente complexa e permanente.

Analisando-se o momento fático brasileiro da contemporaneidade, salta aos olhos a desigualdade social que marca o país. Tal é a intensidade dessa característica que até mesmo as regiões e os Estados membros brasileiros apresentam elevado grau de desigualdade entre si, corroborando para a construção de uma nação marcada pela baixa efetividade dos direitos fundamentais por ela positivados.

Somente por meio de políticas públicas eficientes que o Estado brasileiro irá superar tal cenário de crise, uma constante desde os seus primórdios. Os incentivos fiscais, nesse contexto, apresentam-se como mecanismo ou instrumento de programas de políticas públicas 
maiores, devendo, assim, estas serem analisadas e avaliadas, para que se torne possível compreender os caminhos que estão sendo tomados pela federação brasileira.

\section{REFERNÊNCIAS BIBLIOGRÁFICAS}

ACEMOGLU, Daron; ROBINSON, James. Por que as nações fracassam - A origem do poder, da prosperidade e da pobreza. Rio de Janeiro, Elsevier, 2012.

ADEODATO, João Maurício. Uma teoria retórico da norma jurídica e do direito subjetivo. São Paulo: Noeses, 2011.

AITH, Fernando. Políticas públicas de Estado e de governo: instrumentos de consolidação do Estado Democrático de Direito e de promoção e proteção dos direitos humanos. In BUCCI, Maria Paula Dallari (org.). Políticas Públicas - Reflexões sobre o conceito jurídico. São Paulo: Saraiva, 2006, p. 217-245.

ALEXY, Robert. Teoría de los Derechos Fundamentales. Trad. Ernesto Farzón Valdés, Madrid: Centro de Estúdios Constitucionales, 1993.

BARROSO, Luís Roberto. Interpretação e Aplicação da Constituição: fundamentos para uma dogmática constitucional trasnformadora. 5. ed. São Paulo: Saraiva, 2003.

BARROSO, Luís Roberto. O constitucionalismo democrático no Brasil: crônica de um sucesso imprevisto. 2012. Disponível em: https://www.migalhas.com.br/dePeso/16,MI168919,51045-

O+constitucionalismo+democratico+no+Brasil+cronica+de+um+sucesso>. Acesso em $08 \mathrm{de}$ fevereiro de 2020.

BERCOVICI, Gilberto. Constituição e superação das desigualdades regionais. In: GRAU, Eros e GUERRA FILHO, Willis Santiago (orgs). Direito Constitucional: estudos em homenagem a Paulo Bonavides. $1^{a}$ ed., $2^{a}$ Tiragem. São Paulo: Malheiros, 2003, p. 74-107.

BERCOVICI, Gilberto. Planejamento e políticas públicas: por uma nova compreensão do papel do Estado. In BUCCI, Maria Paula Dallari (org). Políticas Públicas: reflexões sobre o conceito jurídico. São Paulo: Saraiva, 2006, p. 143-161.

BEVILACQUA, Lucas. Incentivos fiscais de ICMS e desenvolvimento regional. São Paulo: Quartier Latin, 2013.

BRASIL. Constituição Federal, de 05 de outubro de 1988. Diário Oficial da República Federativa do Brasil, 05 de outubro de 1988.

BUISSA, Leonardo. Tributação sobre o consumo no Estado Federal, indução econômica e integração. Tese de doutorado USP, 2016, p. 182-197.

CALIENDO, Paulo. Reserva do possível, direitos fundamentais e tributação. In: SARLET, Ingo Wolfgang e TIMM, Luciano Benetti. Direitos Fundamentais: orçamento e "reserva do possível". Porto Alegre: Livraria do Advogado Editora, 2008, p. 195-208.

CHEVALLIER, Jacques. O Estado Pós-Moderno. Trad. Marçal Justen Filho. Belo Horizonte: Fórum, 2009 (p.59-98).

COELHO, Saulo de Oliveira. Reconhecimento, Experiência e Historicidade: considerações para uma compreensão dos Direitos Humano-Fundamentais como (in)variáveis principiológicas do Direito nas sociedades democráticas contemporâneas. In: SOBREIA; 
FARIAS; OLIVEIRA JR. Filosofia do Direito. Florianópolis: Conpedi/FUNJAB, 2012, p. 289-310

COELHO, Saulo Pinto Coelho. Desarrollo Humano Crítico-Inclusivo: crítica del derecho al desarrollo y desarrollo crítico del derecho. In: Moyano; Coelho; Mayos. (Org.). Posdisciplinariedad y Desarrollo Humano: entre pensamiento y política. 1ed.Barcelona: Linkgua, 2014, v., p. 41-63.

COELHO. Para uma crítica das críticas ao discurso dos direitos humanos e fundamentais: da desconstrução do jushumanismo ao jushumanismo crítico. Revista Direitos Humanos e Efetividade, v. 1, p. 1-18, 2015.

COELHO, Saulo Pinto Coelho. ASSIS, Alline N. Um constitucionalismo do espetáculo? Espetacularização das políticas públicas e ineficiência do controle jurídico-constitucional. Revista Brasileira de Estudos Políticos, v. 115, p. 541-584, 2017

COELHO, Saulo; PEDRA, Caio. Direitos Humanos entre Discursos e Ideologias: a plurivocidade semântica dos direitos humanos, a necessidade de crítica democrática permanente e o permanente risco de reviravolta autoritária. In: Direitos Fundamentais e Democracia. 1ed. Florianópolis: Funjab, 2013, v. I, p. 173-192

CONTI, José Maurício. Considerações sobre o Federalismo Fiscal brasileiro em uma perspectiva comparada. In: CONTI, José Maurício; SCAFF, Fernando Facury; BRAGA, Carlos Eduardo Faraco (Org.). Federalismo fiscal: questões contemporâneas. Florianópolis: Conceito Editorial, 2010, p. 15-34.

CORREIA NETO, Celso de Barros. O avesso do tributo: incentivos e renúncias fiscais no Direito brasileiro. São Paulo: Almedina Brasil, 2014, p. 125-162.

COUTINHO, Diogo R. O direito nas políticas públicas. MARQUES, Eduardo e FARIA, Carlos Aurélio Pimenta de. Política Pública como Campo Multidisciplinar. São Paulo. Ed. UNESP.

COUTO, Cláudio Gonçalves. Sistema de governo e políticas públicas / Cláudio Gonçalves Couto -- Brasília: Enap, 2019.

DOMINGOS, Sérgio. A eficácia dos direitos fundamentais. Rev. Fund. Esc. Super. Minist. Público Dist. Fed. Territ., Brasília, Ano 10, Volume 19, p. 191-216, jan./jun. 2002.

FARIA, Luiz Alberto Gurgel. A extrafiscalidade e a concretização do princípio da redução das desigualdades regionais. 1 ed. São Paulo, Quartier Latin, 2010.

FONSECA, Pedro Cezar Dutra. Desenvolvimentismo: a construção do conceito. Texto para discussão / Instituto de Pesquisa Econômica Aplicada.- Brasília: Rio de Janeiro: Ipea, jul. 2015.

FONSECA, Pedro Cezar Dutra e SALOMÃO, Ivan Colangelo. O sentido histórico do desenvolvimentismo e sua atualidade. Revista de Economia Contemporânea, 2017. Número especial: p. 1-20.

FURTADO, Celso. Formação Econômica do Brasil. 34 ed. São Paulo, Companhia das Letras, 2016.

GOZZI, Gustavo. O Estado Contemporâneo. In: BOBBIO; MATTEUCCI; PASQUINO. Dicionário de Política. Brasília: UnB, 2007, p. 401-409.

GRIN, Eduardo José. Governos locais: uma leitura introdutória / Eduardo José Grin; Fernando Luiz Abrucio - Brasília: Enap, 2019.

HOLMES, Stephen e SUSTEIN, Cass S. The cost of rights. Why liberty depends on taxes. New York/London: WW Norton \&amp; Company, 1999.

HUMBERTO ÁVILA. Competências Tributárias - um ensaio sobre a sua compatibilidade com as noções de tipo e conceito. São Paulo, Malheiros, 2018. 
JUSTEN FILHO. Conceito de interesse público e a personalização do direito administrativo. In Revista Trimestral de Direito Público, n. 26, São Paulo: Malheiros, 1999.

MARTINS, Alexandre Marques da Silva. Os valores em Miguel Reale. Brasília a. 45 n. 180 out./dez. 2008

MONTEIRO NETO, Aristides. Desigualdades regionais no Brasil: características e tendências recentes. Boletim regional, urbano e ambiental. IPEA, 2014.

MOREIRA NETO, Diogo de Figueiredo. Mutações do Direito Administrativo, $3^{\mathrm{a}}$ ed. Rio de Janeiro: Renovar, 2007 (p.7-36).

PIKETTY, Thomas. O Capital no Século XXI. 1. ed. Rio de Janeiro: Intrínseca, 2014.

REALE, Miguel. Direito como experiência: introdução à epistemologia jurídica. - 2. ed. - São Paulo: Saraiva, 1992.

REALE, Miguel. Experiência e cultura. Campinas: Bookseller, 2000.

REALE, Miguel. Teoria do Direito e do Estado. 5. ed. São Paulo: Saraiva, 2000.

REALE, Miguel. Teoria Tridimensional do Direito. São Paulo: Saraiva, 2010.

REI, José Anijar Fragoso. Benefícios fiscais de ICMS para a efetivação de direitos fundamentais. 2017.

SALGADO, Joaquim Carlos. O Estado Ético e o Estado Poiético. Revista do Tribunal de Contas do Estado de Minas Gerais, Belo Horizonte, v. 27, n. 2, p. 37-68, abr.jun. 1998.

SARLET, Ingo Wolfgang. A eficácia dos direitos fundamentais. Porto Alegre: Livraria do Advogado, 2010.

SCAFF, Fernando Facury. Orçamento Republicano e Liberdade Igual. Belo Horizonte:

Fórum, 2018, p. 41-86.

SCHMIDT, João Pedro. Para entender as políticas públicas: aspectos conceituais e metodológicos. In: REIS, Jorge Renado; Leal, Rogério Gesta (orgs.). Direitos Sociais e políticas públicas: desafios contemporâneos. Santa Cruz do Sul: EDUNISC, 2008.

SEN, Amartya. Desenvolvimento com liberdade. São Paulo: Companhia das Letras, 2010.

SILVA, Vírgílio Afonso. O Judiciário e as políticas públicas: entre transformação social e obstáculo à realização dos direitos sociais. In SOUZA NETO, Cláudio Pereira de e SARMENTO, Daniel. Direito Sociais: fundamentação, judicialização e direitos sociais em espécies. Rio de Janeiro: Lumen Juris, 2008, p. 587-599.

SMANIO, Gianpaolo Poggio e BERTOLIN, Patrícia Tuma Martins (orgs.). O Direito e as Políticas Públicas no Brasil. São Paulo, Atlas, 2013. pp. 1-62

TORRES, Heleno Taveira. Constituição financeira e o federalismo financeiro cooperativo equilibrado brasileiro. In Revista Fórum de Direito Financeiro e Econômico n. 5, mar./ago.2014, p.25-54.

SUNDFELD, Carlos Ari. Direito Administrativo para Céticos. São Paulo: Malheiros, 2012. (p.231-280) 